\title{
Smart industry or smart bubbles? \\ A critical analysis of its perceived value.
}

Paper presented at 7th e-HRM conference "Humanity of e-HRM" 2018, Milan, Italy.

Milou Habraken*

Human resource management

University of Twente

The Netherlands

m.m.p.habraken@utwente.nl

*corresponding author

\section{Tanya Bondarouk}

Human resource management

University of Twente

The Netherlands

t.bondarouk@utwente.nl

\section{ABSTRACT}

Despite the fact that labels such as smart industry and industry 4.0, terms used to denote the fourth industrial revolution, have become popular topics within academia and practice their meaning remains an issue of concern. The absence of a clear understanding or identity of these labels is a struggle that has been raised repeatedly and received attention by various authors. It is a struggle we engage in as well to crystallize our central focus which goes much deeper by means of asking the question: what does smart industry bring to the scholarly and practical table? To answer this question we conducted an interview-based research with twenty smart industry experts. Obtained results showed that smart industry is more complex than the descriptions within official reports. Smart industry is thus not as straightforward as initially assumed and therein lies its value - highlighting the multiplicity and complexity of current developments. Academia further benefits from smart industry due to the new research directions it stimulates. The label itself, however, holds less relevance for academia. Given the extent of overlap with industry 4.0 identified so far, we recommend to aim for more conformity among the diversity by adopting the label industry 4.0 over smart industry.

Keywords: fourth industrial revolution, smart industry, industry 4.0, meaning, value 
"The industrial world has never before known this freedom” (p.53) "New technologies appear; long-established businesses fall on hard times; the economic order is threatened; and society itself experiences drastic challenges to values and standards of behaviour" (p.54) -

“There are many unknows” (p.64) Although the above quotes address the third industrial revolution (Finkelstein \& Newman, 1984) they are just as relevant in the current day situation since, once again, we seem to be facing economic upheaval. In other words, following the first three periods of turmoil (1) water and steam power leading to mechanical production; (2) electricity and division of labour enabling mass production; and (3) electronics and information technology driving further automation of production, it is claimed that we now find ourselves in the early stages of a fourth industrial revolution. Note here the phrasing of early stages as it is unique that an industrial revolution is announced a priori (Drath \& Horch, 2014). An additional aspect of interest regarding this new revolution are the many different labels used to denote the phenomenon such as smart industry and industry 4.0 (Davies, 2015; Hermann, Pentek, \& Otto, 2016). A more common aspect, as it has been a part of every major technological change, is the resurfacing of the debate on whether or not the future will hold massive unemployment (see Habraken \& Bondarouk (2017) for a detailed discussion on the employment debate). The presence of this debate, however, lies in stark contrast to the multiple optimistic outcomes which are being attributed to smart industry or industry 4.0. It is for instance presumed that these labels will deliver more flexibility, enhanced customer interaction, alter business models and deal with some of the bigger societal challenges like demographic change (Huizinga et al., 2014, April; Kagermann, Wahlster, \& Helbig, 2013). Given the promises made regarding the industrial and social effects of the fourth industrial revolution as well as the phase of the current revolution, it is not surprising that the labels smart industry and industry 4.0 have become a popular topic within universities, companies and at conferences, both practice and academia oriented.

What continues to be worrisome, especially considering the amount of fascination for the labels smart industry or industry 4.0 , is the lack of understanding with respect to these terms. Though the third revolution was also known as the computer revolution, its reference to computerization provided more insight than the names of current labels do. The diverse lists of technologies and/or future visions often linked to smart industry or industry 4.0 neither offers much clarity. Consequently, the absence of a clear understanding or identity of these labels is an issue which has been raised repeatedly and has recently been addressed by various authors (Hermann et al., 2016; Liao, Deschamps, Loures, \& Ramos, 2017; Reischauer, 2018). The 
obtainment of a clearer meaning can thus be seen as a unique and relevant struggle. A struggle we will engage in to crystallize our central focus which goes much deeper. That is, we aim to answer a fundamental question that underlies the stated struggle. Apart from understanding a new label it is just as essential to know its value. To ask whether it is worth retaining, hence in what way does the adoption of these terms aid us scientifically and practically speaking? Take for instance the paper by Cascio and Montealegre (2016). It highlights the technological developments that are upon us and covers its influence on work and employment. Yet, apart from a brief mention of the term 'new industrial revolution' respected authors do not use the mentioned labels. The logical scholarly curiosity takes off here - why to debate about a definition if it is not widely adopted and/or does not help in advancing our research? In other words, we suggest to reflect on the meaning and the value of the term smart industry. Current study focuses on only one of the two labels since no concrete evidence exists as to the extent of overlap between them; whether they can truly be used interchangeably. We chose to focus on smart industry for two reasons: firstly existing papers aiming to obtain a clearer understanding have so far only looked at industry 4.0. By focusing on smart industry we will contribute new insights towards this issue. Secondly, industry 4.0 is a label which seems to be used more often in comparison to smart industry. For example a Web of Science search on "industry 4.0" vs. “smart industry”, with time span 2011-2018, results respectively in 1,800 vs. 35 records (on September 20, 2018). This makes the question regarding its value even more relevant. As a result, our research question reads: what does smart industry bring to the scholarly and practical table? To answer this question, an understanding of the term smart industry asks for a careful deliberation. For this, we conducted an interview-based research with smart industry experts.

The remainder of this paper is structured as follows: first we briefly illustrate the manner in which smart industry is depicted in reports from the Dutch smart industry team, the value of the label that stems from those depictions and the confusion that occurs. Next, the research process is outlined after which we present the results from the conducted interviews. On the basis of these findings a viewpoint of smart industry is developed. Using this perspective, we finally turn to our question of what smart industry brings to the scholarly and practical table.

\section{TECHNOLOGICAL DETERMINISM?}

While the term industry 4.0 which grew out of the German name industrie 4.0 and became a recognized catch word since its public debut during the Hannover Trade Fair in 2011 (Hermann et al., 2016), the label smart industry originates from the Netherlands. The first official mention can be found in the Dutch report from April 2014 (Huizinga et al., 2014, April). The team 
behind this report consists of five important parties: the ministry of economic affairs, the chamber of commerce (KvK), the Dutch employers' organisation for the technology industry (FME), the Netherlands organisation for applied scientific research (TNO) and the confederation of Netherlands industry and employers (VNO-NCW). Within this report, smart industry is defined as a strategic vision of the future industry. Such industries are stated to have flexibility in production, being able to (fine)tune to customers' needs and make use of entire supply chain for value creation. Subsequently, these outcomes are said to be enabled by a network-centric approach, making use of value of information, ICT and latest available proven manufacturing techniques. A recap of this description can be found further in the report when it mentions that "smart industry - driven by information, digitization, networks and manufacturing technologies - will improve quality, increase flexibility, increase automation, enhance participation within the value chain and enhance interaction with customers” (Huizinga et al., 2014, April, p. 25). Smart industry is therefore seen as a future view of industry stemming from technology. It reflects a cause and effect chain where the origin of the change is viewed from a technological stand point. Technology is treated here as an independent influence on organisational properties and the mutual impact of humans is ignored. We clearly see that this discussion turns us back to the debate about deterministic views of technology, broadly discussed in 1990s. In other words, the above descriptions as well as descriptions that can be found in other documents (e.g. Ahsmann et al., 2018, February 5; Berentsen et al., 2014, November 1) adopt a technological imperative approach to smart industry (Orlikowski, 1992; Strohmeier, 2009). Comparing smart industry then with the term industrial revolution - “a rapid major change in an economy (as in England in the late $18^{\text {th }}$ century) marked by the general introduction of power-driven machinery or by an important change in the prevailing types and methods of use of such machines” ("Industrial revolution," n.d.) - does not seem to add much apart from a change in level of detail. Both the term industrial revolution and smart industry adopt a strict deterministic approach but the latter contributes more specifics regarding the technological enablers and predicted outcomes. These specifications, however, could also be encapsulated in the addition of the word 'fourth'. Based on these descriptions, one could question whether smart industry offers enough.

Yet, smart industry documents offer signs that point towards a less strict deterministic approach. Though scares, other descriptions exist as well: "the previous sections mainly dealt with technologies, but this is too limited. Experience shows that the implementation of technologies for the purpose of benefiting from its opportunities takes special expertise and an innovative attitude" and "smart industry is about more than technological developments, ICT 
and different business models. It is the employee who will have to make a difference and it is important that the employee has the right skills and knowledge” (Huizinga et al., 2014, April, p. 22; Teamsmartindustry, 2015, p. 2). They add a moderating effect, specifically the contextual variable 'skilled workforce', to the causal chain stated earlier. In so doing, a more moderate deterministic or contingency model is adopted (Orlikowski, 1992; Strohmeier, 2009). In sum, the first official definition of smart industry and even the more recent one from $2018^{1}$ phrase the label in quite a strict deterministic manner. However, several notions can be found that depict a different story, hence nuances are visible which can impact the added value of labels such as smart industry. As a result, we aim to gain insights into the nuances that appear to be present in the term smart industry, via interviews, to unravel what it brings to the table.

\section{METHOD}

\section{Participants and procedure}

Next to the program office and the steering committee, the Dutch smart industry team consists of a forum group whose members represent a diverse set of sectors (e.g. agrifood, chemistry, life science \& health) and are tasked with creating support, stimulating, connecting, exchanging knowledge, realizing togetherness and making bottlenecks negotiable and solvable ("Forum," n.d.). Given this role and diversity of the members of the smart industry forum we approached them $^{2}$, via email, with the question whether they would like to discuss the meaning of smart industry. The interviews were held between December 2016 and February 2017. After fifteen interviews data saturation started to occur. To achieve full saturation additional five interviews were conducted to prevent essential aspects of smart industry from being overlooked. Consequently, we conducted twenty interviews in total. Of these participants fifteen were members, or appointed alternatives, of the smart industry forum group. Five participants were non-forum members but stemmed from recommendations who indicated these participants to be knowledgeable and actively involved in smart industry. In line with the goal of the study we held the interviews as open conversations and we asked respondents how they viewed, defined, interpreted and/or which aspects they connected to smart industry. Participants were further triggered to provide examples in relation to given answers in case they did not do so themselves. Remaining questions depended on the responses that were given to the main question.

\footnotetext{
1 "Smart Industry is about future-proof industrial \& product systems; these are smart and interconnected and make use of Cyber Physical Systems. Digitization, connectivity and new manufacturing \& product technology are drivers for this” (Ahsmann et al., 2018, February 5, p. 9).

${ }^{2}$ The study is based on the composition of the smart industry forum on November 2016.
} 
Interviews lasted an average of 47 minutes and where possible were digitally recorded; this was the case for seventeen out of the twenty interviews. We transcribed the recorded interviews verbatim (resulting in 106.315 words of transcripts) and emailed them to the participants with an invitation to 'review it and send any comments'. Participants were asked to return any feedback or corrections within two weeks. All edits received were taking into account in the data analysis.

\section{Data analysis}

Using Atlas.ti, we firstly open coded all transcripts. Chunks of text received codes based on the content that was being discussed in that segment (e.g. background on prior industrial revolutions) or terms that were explicitly stated in that part (e.g. 3D printing, zero-defect, big data). In subsequent rounds we only considered pieces of text which contained codes that were of relevance to the research goal of this paper - unravelling smart industry. Consequently, segments that contained codes addressing, for instance, the earlier mentioned industrial revolution background, insights into the Dutch smart industry team or information on the German industry 4.0 term were omitted. The next rounds of analysis were used to develop the remaining codes resulting in codes with similar meanings being bundled under one new code (e.g. codes such as internet, IT, digitalization were combined to form the code 'digitized'). In addition, the various codes representing new (non)physical assets - for example drones, block chain, augmented reality - were combined to form the new code 'equipped'. Finally, four headings were created to group several related codes. These headings contained codes associated with the expected changes in output of organisations (i.e. products) or the production phase (i.e. production process) and contained organisational departments (i.e. other processes) or types of interactions (i.e. relations) expected to be subject to change. Eventually, thirty-one codes remained which we checked and found fitting with the notes taken during the three nonrecorded interviews. The analysis of these written notes did not result in the necessity to add new codes to the thirty-one identified from the transcripts. After the initial open coding process, we applied axial coding on the thirty-one codes found. This process resulted in the identification of four distinct categories: intended rationales, key developments, preconditions and expected impacts. These four categories originated from the examination of the type of words or phrases used within pieces of texts belonging to the thirty-one codes (Table 1). 
Table 1. Examples of wording/phrasing and supporting quotes for each of the four identified categories

\begin{tabular}{|c|c|c|}
\hline Category & Notable phrasing & Example quotes \\
\hline $\begin{array}{l}\text { Intended } \\
\text { rationales }\end{array}$ & $\begin{array}{l}\text { The wording or phrasing } \\
\text { used express rationales for; } \\
\text { e.g.: } \\
\text { so that ; original purpose ; } \\
\text { really to ; has to do with ; we } \\
\text { need to ; ultimately it is ; we } \\
\text { want to maintain ; } \\
\text { understand or see that }\end{array}$ & $\begin{array}{l}\text { The original goal was mainly making sure that the Dutch } \\
\text { manufacturing industry would not miss the boat given the } \\
\text { digitization of its industry (R4) } \\
\text { Thirdly, you see that to remain competitive you have to keep } \\
\text { up with current advancements, so as manufacturing companies } \\
\text { you have to excel in the area of digitization, robots, et cetera } \\
\text { (R2) } \\
\text { We would create a response to industry 4.0, hence what this } \\
\text { would mean for the Netherlands. So that we could present that } \\
\text { on the Hannover Messe (R5) }\end{array}$ \\
\hline $\begin{array}{c}\text { Key } \\
\text { developments }\end{array}$ & $\begin{array}{l}\text { The wording or phrasing } \\
\text { used indicate the essence of; } \\
\qquad \text { e.g.: } \\
\text { Play important role ; facing } \\
\text { us ; introduction of } \\
\text { formulated within } \\
\text { enumerations ; stated as an } \\
\text { antecedent in comprehensive } \\
\text { descriptions }\end{array}$ & $\begin{array}{l}\text { And I think that is also were the breadth comes from, if you } \\
\text { look at the internet of things - which is really about getting } \\
\text { devices connected to the internet - a number of technologies } \\
\text { immediately come together namely: those devices know } \\
\text { something about their current state via sensors so you get a } \\
\text { large piece of sensor technology, communication technology } \\
\text { is involved since the devices are connected and subsequently } \\
\text { there are all sorts of big data and artificial intelligence machine } \\
\text { learning aspects involved to, for instance, arrive at new } \\
\text { insights on the basis of those data (R9) } \\
\text { A few things play an extremely important role within the } \\
\text { manufacturing industry. Firstly, are the robots, robotics. } \\
\text { Thanks to the use of robots we can: make a production process } \\
\text { more flexible and provide higher quality products (R2) } \\
\text { Another theme that is facing us, but which has difficulty with } \\
\text { finding solid ground, is nanotechnology (R7) }\end{array}$ \\
\hline Preconditions & $\begin{array}{l}\text { The wording or phrasing } \\
\text { used express required } \\
\text { necessities; e.g.: } \\
\text { then at least you know ; must } \\
\text {; will play a role ; condition ; } \\
\text { important ; unsustainable }\end{array}$ & $\begin{array}{l}\text { Because you can bring technology in but you will have to get } \\
\text { your people on board (R8) } \\
\text { The whole security question but also the question of to whom } \\
\text { does the data belong to becomes an issue with the increase in } \\
\text { digital exchange of information (R17) } \\
\text { So there are quite a few boundary/basic conditions like big } \\
\text { data security and standardization (R5) }\end{array}$ \\
\hline $\begin{array}{l}\text { Expected } \\
\text { impacts }\end{array}$ & $\begin{array}{l}\text { The wording or phrasing } \\
\text { used express change; e.g.: } \\
\text { that means that ; } \\
\text { consequence of ; affects } \\
\text { given comparison then and } \\
\text { now ; stated as an outcome } \\
\text { in descriptions }\end{array}$ & $\begin{array}{l}\text { That is the result of the IoT, that you can discuss with your } \\
\text { customers in a whole different way (R1) } \\
\text { If I look at what the digitization means for us, than firstly it } \\
\text { means a great deal for the product we make (R12) } \\
\text { Look, industry } 4.0 \text { will affect all production processes and the } \\
\text { infrastructure of every business in the Netherlands. And so } \\
\text { whether it is about robots, 3D printing or internet of things, it } \\
\text { affects the core of business processes (R11) }\end{array}$ \\
\hline
\end{tabular}

Note. Numbers between brackets, (R...), refer to a specific respondent

\section{FINDINGS: THE MEANING OF SMART INDUSTRY ACCORDING TO EXPERTS}

An important element that stemmed from the conducted interviews was the fact that smart industry is seen as a genuinely broad term. Not only was this pointed out by respondents themselves, for starters, smart industry is a very broad term, very comprehensive (R16), it also became evident from the number of identified codes as a result of the question how respondents viewed, defined, interpreted and/or which aspects they connected to smart industry. These 
codes are discussed below under their respective category: intended rationales, key developments, preconditions and expected impacts (Figure 1, page 11). We further discovered that though the Dutch smart industry platform adopted a narrow interpretation of the term industry to create focus for their platform, the aspects highlighted by the respondents can be considered as being relevant across industries. An example quote supporting this statement is: in fact, the broadest definition of smart industry is how the entire business community gets started with the fourth industrial revolution. Industry is then considered in the broadest sense of the word, so we are talking about hospitals, educational-, provincial- and municipal institutions, real businesses and business services. Frankly, that is the broad definition which I, not so much the steering committee, but I find important as social development. Eventually, it will impact every profession, industry, company and institution in the Netherlands (R11).

\section{Intended rationales}

Smart industry was addressed as a response to industry 4.0 in the sense that it presented what industry 4.0 means for the Netherlands. Two broader covered rationales were 'alerting the industry', the creation of awareness for and acceleration of the changes that are underway and the establishment of support options herein, and 'competitiveness' which referred to the importance of preserving the continued existence of organisations and the Dutch welfare. We found these latter two motives to be closely linked to each other; example quotes displaying this link are: we have to wake our people up. We have to show them what it all means, what the possibilities, opportunities and threats are. For an SME often indicates being busy with their daily work. So we have to indicate that they should think about their future for otherwise their future is suddenly gone, they end up like Kodak (R7) and anyway this is the objective, accelerating technological innovation and digitalization of the industry and increasing competitiveness of the Dutch industry which is crucial for future prosperity and welfare in the Netherlands (R8).

\section{Key developments}

Four distinct aspects, covered by the majority of the interviewees, were found depicting opportunities that have become available to industry. One such opportunity which we observed is the continued creation of a digital world (digitized). The importance of this aspect became apparent by the frequent use of the word digitization, but also the use of words such as internet, digital, online, electronic indicated the shift towards a more digital context. A second direction that we detected was the possibility of establishing connections between devices and/or systems 
within firms and with external parties worldwide (connected). Respondents again adopted a varied vocabulary to signal the significance of connectivity: internet of things or conjugations of the words connect, link, communicate and talk. The third opportunity highlighted the ability of obtaining and analysing great amounts of real-time data (informed). In other words, there is value in possessing data and the amount of data we can possess has the potential to increase. It, for instance, becomes possible to obtain more information surrounding your product, to be better informed about the status of the production process or how to get the best results; Lelie is able to accurately determine with sensors what food amount, in which composition for which cow leads to the best milk production (R3). The relevance of this development became apparent via the use of either the term big data or simply the word data/information. The final aspect depicts the availability of contemporary (non)physical assets (equipped) such as robots, 3D printers, block chain or nano-technological advancements. A remarkable observation with respect to robots was made since we noticed that different meanings were assigned to this term: (1) an operating robot for production purposes, for example milking robots in the agricultural sector; (2) moving robots, for example a robot donkey in the defence industry; (3) cobots which are collaborative robots that work hand in hand with humans such as an operation robot; and (4) software, for example a self-learning program assessing pictures of skin samples and detecting irregularities/dangerous skin situations.

\section{Preconditions}

The importance of certain preconditions was identified as a third category that emerged from the conducted interviews. A few respondents addressed the aspects arrangements \& legislation, infrastructure, privacy, security and standardization. The first condition referred to the importance of establishing arrangements between businesses - respondents for instance pointed out the remark of who owns the data and the deal between Airbnb and the Amsterdam city council - and awareness for legislation related issues. Mentioned issues were, for instance, whether an ambulance drone is allowed to land everywhere, when to intervene in autonomous systems or the denial of recorded data due to differing legislation between countries. The second requisite implied the presence of supporting infrastructure such as the necessity of an excellent digital connection. Thirdly, respondents discussed the importance of focusing on privacy related issues. Examples that were addressed in relation to this aspect were the discreet handling of personal data by third parties or whether foreign countries receiving data from products that are used here uphold the same cultural value between what is and is not private. The latter two requirements were 'security' and 'standardisation', hence the necessity of cybersecurity and 
standards for establishing communication between various systems/machines. A condition which was discussed by a greater number of respondents was the importance of addressing social issues ${ }^{3}$. Respondents highlighted the necessity for fitting education-, training- and social systems as well as the importance of people's ability to adapt and maintain their value adding capability; you have to be able to bring your people along with you and you will also have to keep retraining them because otherwise, with them, you will not be able to survive in the longterm (R3). Finally, several respondents referred to the importance of the formation of (crosssectoral) collaborations and experimental environments. Its presence and importance became apparent via the use of words such as share with, work together, jointly tackle, combine forces or fieldlabs. The latter term was also described as shared facilities, experimental gardens or learning environments - anyway, it is a place where companies, knowledge institutions and governments, in a specific area, come together in order to achieve innovation (R17).

\section{Expected impacts}

Expected impacts was identified as the fourth category. Two impacts that respondents covered were 'optimisation' - the realisation of efficiency - and the notion of 'reshoring'; a respondent for instance mentioned it is again worthwhile to bring back production (R16). The aspect 'value proposition' covers mentioned developments in this area; answers highlighted the potential creation of new propositions alongside existing ones (e.g. BMW offering their own insurance), the potential establishment of new service oriented propositions (e.g. new firms offering services related to transcending knowledge build-up) and the rise of new businesses offering existing propositions in a different manner (e.g. Uber, Airbnb). Next, a number of impacts were grouped under one of the following headings: products, production process, other processes and relations. Aspects grouped under the heading products reflected changes within products. Respondents specifically pointed out the shift towards tailor made products and the shift from the provision of physical products to services (servicification); an example was for instance, selling the service light instead of lamps. Additionally, respondents addressed the general advancement towards smarter, hence more intelligent, complex, autonomous products made, potentially, from materials with new properties. For instance smart refrigerators or a walker which stops automatically if you are in danger of accessing the highway. The second heading, production process, contained aspects that reflected changes in firms production process. Again, two specific developments became evident from the conducted interviews: the shift

\footnotetext{
${ }^{3}$ This fact however could have been influenced by the authors more social field of research.
} 
towards a more flexible production processes and the shift towards greater control on quality. The latter aspect, was mainly signalled by the word zero defect manufacturing but one respondent, for instance, also mentioned that current developments could lead to the method of treatment becoming much more accurate. Respondents further discussed shift towards managing operations from a distance and the, continuing, conversion to largely automatic operations. Like the previous two headings, the label other processes captured changes within processes beside production. While respondents only stated their expectation that the design process is subject to change or briefly highlighted that administration processes are being automated, more detailed answers were found regarding the logistic and maintenance process. Discussed impacts for the logistic process were, for example, the possible introduction of Uber related concepts or autonomous trucks as well as the disappearance of transportation routes $-a$ book publisher does not need to send physical copies to Amazon, but must now have a connection with the printer at Amazon (R1). On a more positive note, current developments were addressed as being able to potentially offer solutions to the last mile problem. Provided answers pertaining to the maintenance processes signalled a shift towards a more predictive/condition-based and remote maintenance process. Mentioned examples for the latter case were skyping with a maintenance engineer or having a helpdesk assist someone with the aid of team viewer. With respect to the heading relationships a distinction could be made between answers that reflected the impact towards relations with 'suppliers' - the shift towards more automatic and better aligned supplier networks - or those with 'customers' which implied the shift towards closer relations with them. Example quotes are respectively: that the players in the chain are more aligned to each other (R10) and so what we see here is that we are addressing and solving certain problems together with the customer (R6). Finally, respondents discussed expected alterations of existing occupations. Although some respondents highlighted the disappearance of certain jobs - for instance, the replacement of cabdrivers and security guards by autonomous cars and robots - most respondents pointed out the fact that jobs will evolve with the present developments. For example, surgeons operating alongside robots or receiving treatment methods from databanks, farmers monitoring the well-being of their crops/animals from a remote data centre, welders who do not physically weld anymore but assess and interpret the output of robots or camera images that they receive and mechanics that skype with a customer and are faced with new operations due to the emergence of new products. In addition, two respondents addressed the notion of teamwork. Indicating that teamwork, whether with people from various departments internally or with external parties, will be required more frequently in the future. This notion will undoubtedly effect existing jobs. 


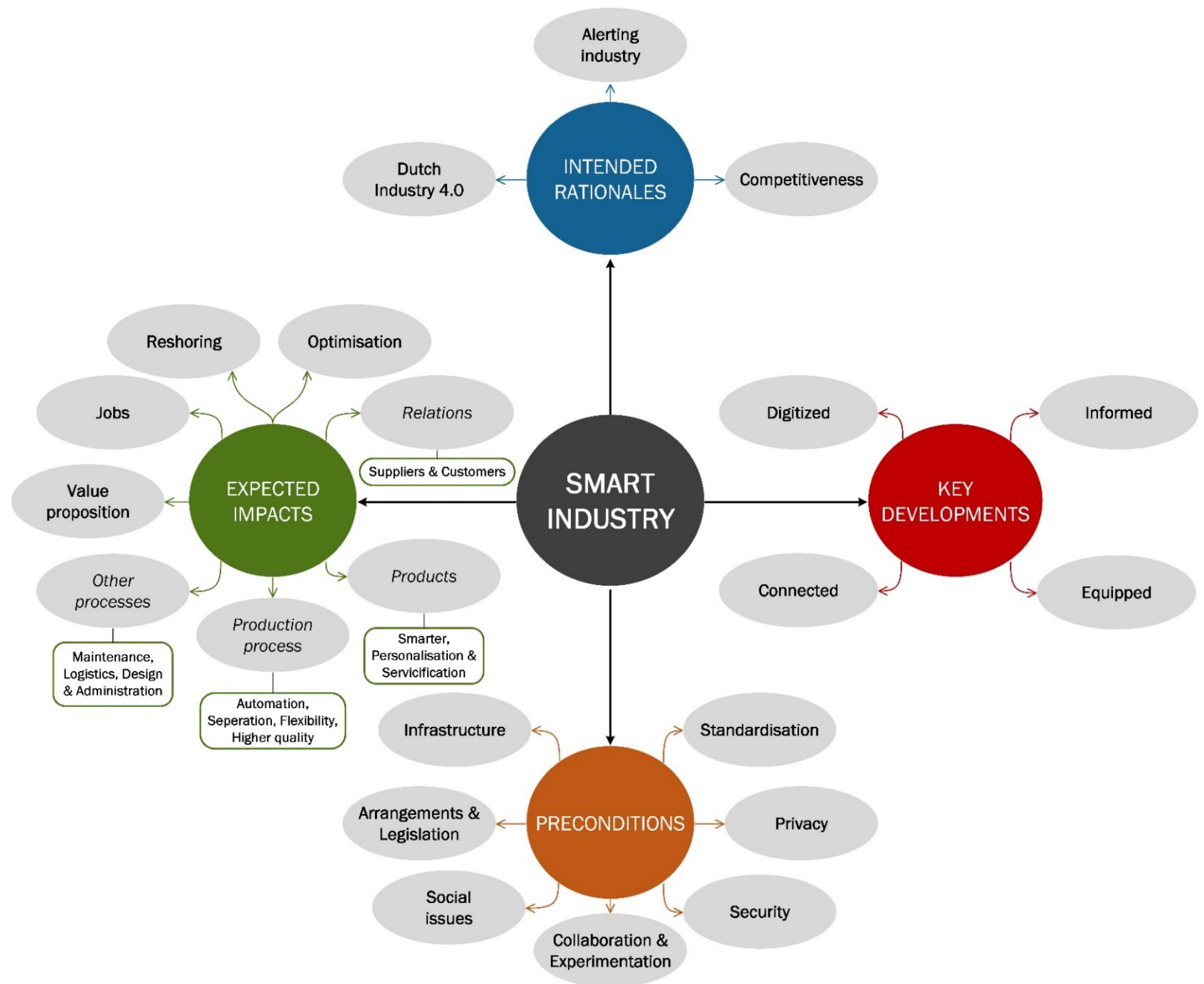

Figure 1. Developed codes \& categories pertaining to smart industry. Stemming from conducted interviews 


\section{A NEW VIEWPOINT OF SMART INDUSTRY}

The interview results showed that the label smart industry is not as straightforward as the initial descriptions lead it to believe. In contrast to the technological imperative approach to smart industry, our data showed that a broader set of factors needs to be taken into account. We integrate these factors into two distinct components: a communicative bubble and a platform for the multiplicity and complexity of current developments. Both components will be discussed in detail below and result in the development of a new smart industry representation.

\section{Communicative bubble}

An aspect that stood out from the answers provided by interviewees were the notions of alerting industry and competitiveness. In other words, obtained results depicted the presence of a human desire to establish a means to communicate a sense of importance, specifically towards the manufacturing industry, regarding emerging opportunities or technological developments. A tool that could be used to promote innovation. It is assumed that, to achieve the desired sense of urgency and promote innovation, the expectations of a future manufacturing industry (smart industries) emerged. Consequently, the aim behind the communicative action explains the intensive focus on future visions of the industry which can be observed (i.e. original description in reports and the number of codes found under expected impact).

\section{Platform of current developments}

Despite that interviewees often spoke of words such as (big) data, augmented reality, internet of things and block chain, this manner of phrasing current developments signals the existence of a random list of technologies from which one does not become much wiser. The embodiment of main opportunities is therefore taken to a higher level of abstraction. In line with the description of smart industry presented in Huizinga et al. (2014, April) we identified four categories: digitized, connected, informed and equipped. Yet, in our view the category digitized, the continued creation of a digital world, is imbedded in the other three elements. That is, the emerging connections imply a digital format, the value in information becomes a critical factor because of large quantities of information available as a result of data which has been transformed or is natively digital and assets such as augmented reality require a digital component in order to function. Digitized as a stand-alone category is therefore regarded as being redundant. In addition, the establishment of connections is inextricably linked to the collection of information so one could consider combining the categories connected and informed. An explicit distinction between the two categories is, however, made since we want 
to highlight two specific purposes. One being the creation of new information. In other words, the process of working with the obtained data, analysing it and seeking the hidden value within it. The other purpose is more efficiency oriented, the main hero are the networks, where less to no editing of the information takes place (e.g. indicate location, fit with quality settings). Besides the communicative component, smart industry can thus be considered as a platform expressing three technology based developmental streams that exist at the moment: (1) the establishment of connections between devices and/or systems within firms and with external parties worldwide, (2) the ability to take more advantage of the value of information via presence of greater amounts of data and (3) the availability of contemporary (non)physical assets. Note the omission of the word manufacturing in the above enumeration. This was a conscious choice supported by our data and implies that these streams apply everywhere. Additionally, the application of one or more of these streams is restricted by several social and IT related constrains (see Figure 1 and results section) and they are therefore incorporated into the platform component of smart industry. In short, this platform component embodies the multiplicity (three streams) and complexity (conditions) of current developments.

\section{Smart industry}

At its base, the representation of smart industry (Figure 2) illustrates the three technology based developmental streams currently in existence. Given our assumption that the intensive focus on future industry visions emerged out of the desire to promote innovation the communicative bubbles on the left contain predictions pertaining to a future manufacturing industry. We, however, need to remain critical and think about what happens when we look beyond the communicative bubbles. To prick through the commotion of developing awareness and promoting innovation. In essence, the made predictions are not necessarily incorrect. They could stem from current developmental streams but the extent to which these predictions hold true is uncertain and dependent on choices organisations make with regard to the opportunities, hence streams, available. Additionally, these choices are influenced by the extent to which existing constrains are dealt with. The right side therefore incorporates the presence of these restrictions via the prison balls. The rest is kept blank since, to date, we have no precise knowledge on outcomes of choices made. Outcomes that have the potential to alter human actions, positively and negatively, as well as institutional properties like business strategies. We therefore see the communication bubbles, that insist on old fashioned technological imperatives 
where technology postulates organisational reality, as a step-back in scholarly development discussed in full-length by academics (e.g. Orlikowski, 1992; Strohmeier, 2009).

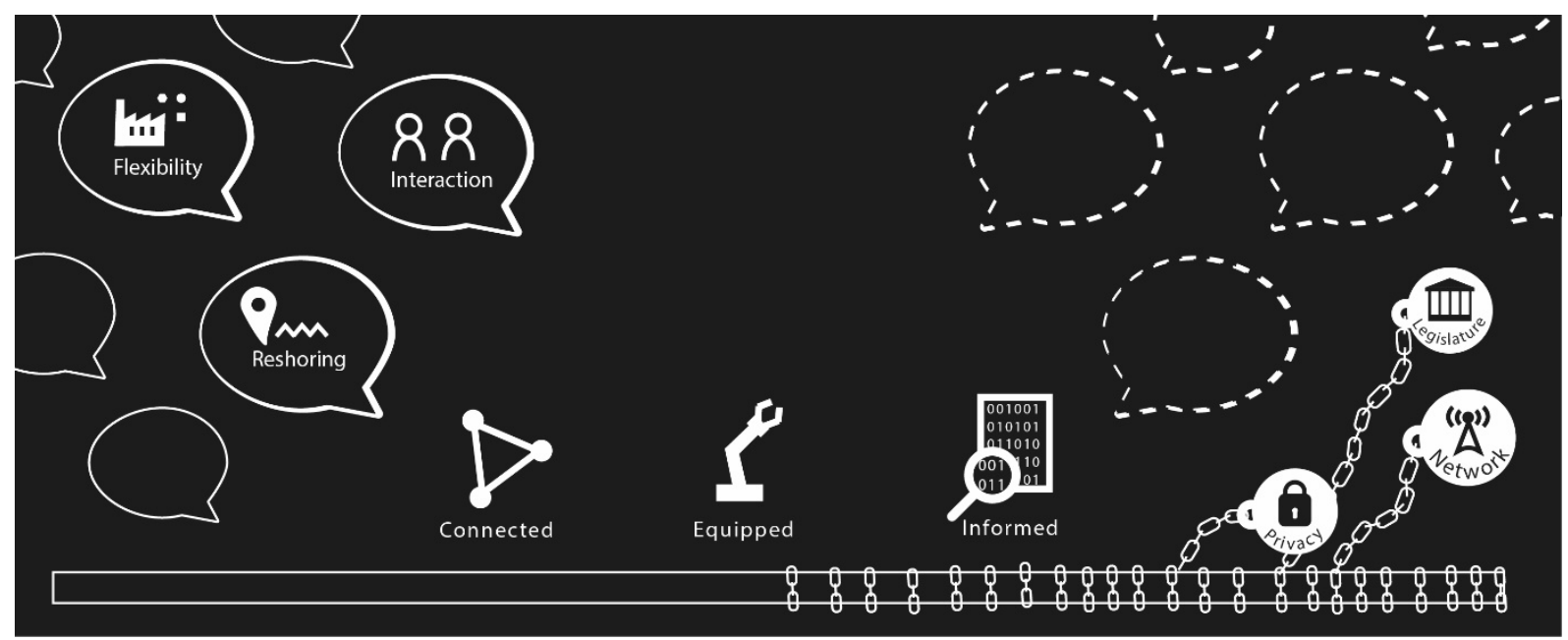

Figure 2. Smart industry. Based on conducted interviews

\section{UNRAVELING THE VALUE - WHAT DOES IT BRING TO THE TABLE?}

Before discussing the value of the specific name given to the examined label, we first address the value of the content of the label, as depicted in Figure 2, for both practice and academia.

\section{Value of the content}

The main value for practice lies in the way the label has been used to create awareness and stimulate innovative action in manufacturing organisations. A noble intention but worrisome given its focus on the created visions of a future manufacturing industry. In other words, shifting the focus of the communicative action to one that highlights the multiplicity and complexity of current developments would likely offer more value. Words like networks, robots or flexibility sell a story but do not aid much in representing the direction of the type of choices and the existing restrictions organisations are facing at the moment - for instance is it beneficial for us to establish connections and should we concentrate on internal or also external networks? Should we invest in robots, why, and what do we imply with this term? Can our infrastructure handle the made decisions? What could we gain by participating in an existing fieldlab or by collaborating with other parties? Adopting the label as a means to visualise the multiplicity and complexity of current developments is not just useful for practice but academia can also benefit from it via the obtainment of an understanding of the context organisations are facing. Nevertheless, the main contributions for academia are the new research questions which the content of the label offers. From a communicative bubble perspective, examples are whether it 
had the intended effect, hence to what extent did it lead to the occurrence of more innovation within the targeted group? What is the network behind this bubble, so who are the initial involved parties, in what way did the network evolve further and how can the relationship of each party be depicted? And how did the structure of the network affect the level of innovation? Research questions that arise when taking a platform perspective are for instance what choices do organisations make with respect to the three technology based developmental streams? What factors impact the choices made and in what way are the associated constrains a factor of significance herein? What are the effects of the implementation of one or more of the developmental streams? This latter question can be considered from a very broad range of perspectives such as human resource management, logistics, supply chain, a more legal or ethical standpoint and so forth. We can thus state that there is value in the content of the label smart industry.

\section{Value of the name smart industry}

The question that remains is whether there is added value in the name smart industry in contrast to designations such as industry 4.0 or the fourth industrial revolution. Regarding the latter term, its strict deterministic or technological imperative standpoint mentioned earlier does not fit the smart industry content described above. Additionally, the attribution of the term revolution to the recent context is questionable since a revolution marks a rapid major change ("Industrial revolution," n.d.) and, although it has the potential of being major, the current developments are slow in its implementation. To demonstrate this statement we briefly highlight some results from a smart industry survey conducted in 2015 and 2016 among members of the Dutch chamber of commerce research panel ${ }^{4}$ (Smetsers \& Borst, 2017). We specifically focus on the questions 'are you familiar with the term smart industry' and 'do you see smart industry as an opportunity, a threat or both' for these represent prerequisites for implementation. In a years' time, familiarity with the term increased from 10 to 15 percent and the answer option 'do not know' in the second question dropped from 48 to 46 percent. These numbers show that progress is slow as well as low. Consequently, the label fourth industrial revolution does not represent the discussed content and, in our opinion, its use as the main designation for current developments should be avoided.

To assess the value of smart industry next to the label industry 4.0 we examine whether components in Figure 2 can be found in relation to industry 4.0. One similarity can be found in

\footnotetext{
${ }^{4}$ Panel members represent a diverse group with respect to gender, age, sector and whether they are an independent entrepreneur or whether they are part of an SME (up to 249 employees).
} 
the fact that Reischauer (2018) as well as Pfeiffer (2017) raised the notion of a communicative bubble with respect to the label industry 4.0. Reischauer (2018, p. 26) suggests to view industry 4.0 as "policy-driven innovation discourse in manufacturing industries that aims to institutionalize innovation systems that encompass business, academia and politics” while Pfeiffer (2017, p. 113) mentions that "industrie 4.0 got its discursive wings not primarily from the rise of new technical possibilities but rather from economic "exigencies" as identified by economic elites”. Our data thus corresponds with views of industry 4.0 being a communicative enabler. A second resemblance exists in the fact that both labels include a set of predictions, or a vision, regarding the manufacturing industry. This is visible from the huge potentials stated in the final report of the German industry 4.0 working group (Kagermann et al., 2013) but can also be derived from the framework of industry 4.0 created by Krüger (2018) on the basis of a constructed literature matrix. This matrix contains data on definitions and components of industry 4.0 identified in official policy documents from eleven different European countries. The framework, subsequently, contains three streams - industry 4.0 as a source of competitive advantage, a social innovation and an organisational tool for re-structuring - whose content resemble the formulation of future visions; examples are faster \& more efficient production, improvement of work quality, interconnection of companies \& value chains (Krüger, 2018). The frequent mention of security, standards and infrastructure as well as less often indicated aspects like collaboration or training in papers on industry 4.0 (Hermann et al., 2016; Kagermann et al., 2013; Pfeiffer, 2017) support our conclusion that restrictions as a result of social and IT related constrains is another element that overlaps. The final component of smart industry to be discussed are the three technology based developmental streams. Within the report by Kagermann et al. (2013), attention focuses solely on the connectivity stream. Nonetheless, three industry 4.0 design principles developed by Hermann et al. (2016) interconnection, information transparency and technical assistance - overlap with our streams. Furthermore, a central stream in the framework developed by Krüger (2018) depicts industry 4.0 as a technological innovation containing elements like internet of things, big data and selflearning machines. In sum, we can detect several signals indicating that the content observed under the label smart industry overlaps with what is being presented under the label industry 4.0. If this conclusion holds true, hence if industry 4.0 researchers can agree on the content presented in Figure 2, we see no reason for the retention of the label smart industry within academia. The preservation of the label industry 4.0, over smart industry, is chosen since this term is already more prevalent in academia. It would thus be more difficult to change industry 4.0 then the other way around. Note however the inclusion of the phrase 'within academia' in 
the above statement. In other words, due to the communicative component the label smart industry has become a much invested in term in the Netherlands (e.g. own logo, national website, documents and events). The same would likely apply to other country specific designations adopted for the promotion of this phenomenon. Changing them would therefore be unfeasible. Consequently, the value of the name smart industry is concentrated to countries, such as the Netherlands, who adopt this term to communicate awareness of current developments and promote innovation.

\section{CONCLUSION}

Despite the fact that labels such as smart industry and industry 4.0 have become a popular topic within academia and practice, their meaning remains an issue of concern. The absence of a clear understanding or identity of these labels is a struggle that has been raised repeatedly and received attention by various authors (Hermann et al., 2016; Liao et al., 2017; Reischauer, 2018). It is a struggle we engaged in as well to crystallize our central focus which goes much deeper by means of asking the question: what does smart industry bring to the scholarly and practical table? To answer this question we conducted an interview-based research with twenty smart industry experts. Obtained results showed that smart industry is more complex than the descriptions within reports from the Dutch smart industry team make believe. In other words, an aspect that stood out from the interview results was the presence of a communicative bubble. A component created out of a human desire to establish a means to communicate a sense of importance, specifically towards the manufacturing industry, regarding emerging technological developments. A noble intention but due to its populistic and technology driven nature it is an intention that worries us since it grabs back to a technological imperative approach of technology. An approach which Orlikowski, back in 1992, already pointed out as furnishing an “incomplete account of technology and its interaction with organisations” (Orlikowski, 1992, p. 400) and that is highlighted as simplistic, empirically questioned and potentially refuted in the paper by Strohmeier (2009). Consequently, though tempting we as academics should not fall prey to the alluring messages that are part of the communicative bubble but should look through them and not forget the treasure many scholars from management information systems gave us since the late 1990's. In sum, rather than returning to a technological imperative approach of technology, current developments should be considered as an interaction between institutional properties, human agents and technology. That is, the decisions made by organisations as well as their appropriation and modification determine the outcome of technology. This outcome in turn can facilitate or constrain human agents (e.g. speed up work, 
make it safer or restrict the use of available skills). In addition, the human actions regarding technology are influenced by institutional properties like the state of knowledge about existing opportunities or necessary requirements such as capable infrastructure. Finally, institutional properties are affected by the technological outcome. The latter for instance has the ability to influence operating procedures, communicative patterns and business strategies. Smart industry is thus not as straightforward as initially assumed and therein also lies its value - highlighting the multiplicity and complexity of current developments. Academia, in addition, benefits from smart industry due to the new research directions it stimulates. The label itself, however, holds less relevance for academia. Given the extent of overlap with industry 4.0 we identified so far, we recommend to aim for more conformity among the existing diversity by adopting the label industry 4.0 over smart industry.

\section{ACKNOWLEDGEMENTS}

The authors are very thankful to Isabel de Waard for her artwork with regard to Figure 2.

\section{REFERENCES}

Ahsmann, B., van den Akker, E., van Baars, G., Baartmans, R., Blankendaal, J., Bossert, R., . .. Thuis, B. (2018, February 5). Smart Industry roadmap: Onderzoeksagenda voor HTSM en ICT en routekaart voor de NWA. Retrieved from https://www.smartindustry.nl/smart-industry-roadmap/

Berentsen, W., Buiting, K., Huizinga, G., Kolk, T., Smit, R., B., T., d’Hond, P., . . Grosfeld, T. (2014, November 1). Actie agenda smart industry: Dutch industry fit for the future. Retrieved from https://www.smartindustry.nl/smart-industry-actieagenda/

Cascio, W. F., \& Montealegre, R. (2016). How technology is changing work and organizations. Annual Review of Organizational Psychology and Organizational Behavior, 3, 349-375.

Davies, R. (2015). Industry 4.0. Digitalisation for productivity and growth. European Parliamentary Research Service Retrieved from http://www.europarl.europa.eu/thinktank/en/document.html?reference=EPRS_BRI(20 15)568337.

Drath, R., \& Horch, A. (2014). Industrie 4.0: Hit or hype? IEEE industrial electronics magazine, 8(2), 56-58.

Finkelstein, J., \& Newman, D. (1984). The third industrial revolution: A special challenge to managers. Organizational Dynamics, 13(1), 53-65.

Forum. (n.d.). Retrieved from https://smartindustry.nl/forum/

Habraken, M., \& Bondarouk, T. (2017). Smart industry research in the field of HRM: Resetting job design as an example of upcoming challenges. In T. Bondarouk, H. J. M. Ruel, \& E. Parry (Eds.), Electronic HRM in the Smart Era (pp. 221-259). Bingley, UK: Emerald Publishing Limited. 
Hermann, M., Pentek, T., \& Otto, B. (2016). Design principles for industrie 4.0 scenarious. Paper presented at the 49th Hawaii International Conference on System Sciences, Koloa, HI, USA

Huizinga, G., Walison, P., Bouws, T., Kramer, F., Van der Beek, H., Tops, P., . . . Grosfeld, T. (2014, April). Smart industry: Dutch industry fit for the future. Retrieved from http://smartindustry.nl/wp-content/uploads/2017/08/opmaak-smart-industry.pdf

Industrial revolution. (n.d.). In Merriam Webster Online, Retrieved from https://www.merriam-webster.com/dictionary/industrial\%20revolution

Kagermann, H., Wahlster, W., \& Helbig, J. (2013). Recommendations for implementing the strategic initiative INDUSTRIE 4.0. Final report of the Industrie 4.0 working group. Retrieved from https://www.acatech.de/Publikation/recommendations-forimplementing-the-strategic-initiative-industrie-4-0-final-report-of-the-industrie-4-0working-group/

Krüger, L. (2018). Developing an industry 4.0 framework: Implications for the role of line managers. (Bachelor thesis), University of Twente, Retrieved from https://essay.utwente.nl/75440/

Liao, Y., Deschamps, F., Loures, E. d. F. R., \& Ramos, L. F. P. (2017). Past, present and future of Industry 4.0-a systematic literature review and research agenda proposal. International Journal of Production Research, 55(12), 3609-3629.

Orlikowski, W. J. (1992). The duality of technology: Rethinking the concept of technology in organizations. Organization science, 3(3), 398-427.

Pfeiffer, S. (2017). The vision of "Industrie 4.0" in the making-a case of future told, tamed, and traded. Nanoethics, 11(1), 107-121.

Reischauer, G. (2018). Industry 4.0 as policy-driven discourse to institutionalize innovation systems in manufacturing. Technological Forecasting and Social Change, 132, 26-33.

Smetsers, D., \& Borst, I. (2017). Smart industry onderzoek 2016. Retrieved from Kamer van Koophandel (KvK): https://www.kvk.nl/advies-en-informatie/innovatie/smartindustry/uitkomsten-onderzoek-smart-industry-2016/

Strohmeier, S. (2009). Concepts of e-HRM consequences: A categorisation, review and suggestion. The International Journal of Human Resource Management, 20(3), 528543.

Teamsmartindustry. (2015). Jaaroverzicht 2015 - Vernieuwing door samenwerking in smart industry. Retrieved from https://www.smartindustry.nl/jaaroverzicht-2015vernieuwing-door-samenwerking-in-smart-industry/ 